\title{
Research Article \\ Effect of Na Doping on the Nanostructures and Electrical Properties of ZnO Nanorod Arrays
}

\author{
Lu Yue, ${ }^{1,2}$ Zhiqiang Zhang, ${ }^{1,2}$ Yanyan Ma, ${ }^{1,2}$ and Wenhui Zhang ${ }^{1,2}$ \\ ${ }^{1}$ Jiangsu Collaborative Innovation Center for Ecological Building Materials and Environmental Protection Equipment, \\ Yancheng Institute of Technology, Yancheng 224051, China \\ ${ }^{2}$ Key Laboratory for Advanced Technology in Environmental Protection of Jiangsu Province, Yancheng Institute of Technology, \\ Yancheng 224051, China
}

Correspondence should be addressed to Wenhui Zhang; zwhuizi000@sina.com

Received 9 March 2016; Accepted 5 May 2016

Academic Editor: Gongming Wang

Copyright (C) $2016 \mathrm{Lu}$ Yue et al. This is an open access article distributed under the Creative Commons Attribution License, which permits unrestricted use, distribution, and reproduction in any medium, provided the original work is properly cited.

The p-type $\mathrm{ZnO}$ nanorod arrays were prepared by doping $\mathrm{Na}$ with hydrothermal method. The structural, electrical, and optical properties were explored by XRD, Hall-effect, PL, and Raman spectra. The carrier concentrations and the mobility of Na-doped $\mathrm{ZnO}$ nanorod arrays are arranged from $1.4 \times 10^{16} \mathrm{~cm}^{-3}$ to $1.7 \times 10^{17} \mathrm{~cm}^{-3}$ and $0.45 \mathrm{~cm}^{2} \mathrm{v}^{-1} \mathrm{~s}^{-1}$ to $106 \mathrm{~cm}^{2} \mathrm{v}^{-1} \mathrm{~s}^{-1}$, respectively.

\section{Introduction}

Zinc oxide $(\mathrm{ZnO})$ is a promising material candidate for photoelectronic devices due to its direct wide electron energy bandgap of $3.37 \mathrm{eV}$ at room temperature and large exciton binding energy of $60 \mathrm{meV}$. $\mathrm{ZnO}$ is conventionally used as a substrate for $\mathrm{GaN}$ and has advantages over $\mathrm{GaN}$ such as larger exciton binding energy, lower refraction index, and shallower acceptor levels. Despite its advantages over GaN, the application of $\mathrm{ZnO}$ in optoelectronics is hampered by the lack of stable p-type doping due to self-compensation by donor-like native defects, low solubility of p-type dopants, and formation of deep acceptor levels [1]. The n-type $\mathrm{ZnO}$ is available even without any intentional doping, but it is very difficult to dope $\mathrm{ZnO}$ p-type. Many groups have realized $\mathrm{p}$ type $\mathrm{ZnO}$ conversion by doping group $\mathrm{V}$ elements ( $\mathrm{N}[2]$, $\mathrm{P}$ [3], As [4], and Sb [5]) and groups I and IB (Li [6], Na [7-9], $\mathrm{K} \mathrm{[10],} \mathrm{Ag}$ [11], and $\mathrm{Cu}[12])$, but the stability was not good. Among the group $\mathrm{V}$ elements, $\mathrm{N}$ is the most suitable dopant because it has about the same ionic radius as $\mathrm{O}$ and thus should readily be substituted on $\mathrm{O}$ sites. Indeed, it remains difficult to achieve good quality p-type conduction in $\mathrm{N}$-doped $\mathrm{ZnO}$ due to either a low dopant solubility or a high defect ionization energy. Theoretically, group I element substituted on Zn sites is shallow acceptors [13], but instead these dopants tend to occupy the interstitial sites, partly due to their small atomic radius, and therefore act mainly as donors. On the other hand, reports of Na-doped p-type $\mathrm{ZnO}$ films are rather poor [14]. Up to now, various methods have been employed to prepare p-type $\mathrm{ZnO}$ including molecular beam epitaxy (MBE) [15], chemical vapor deposition [16], and pulsed laser deposition [17], in which complicated, high temperature deposition and expensive vacuum systems have been employed. In contrast, the hydrothermal method was proven to be an ideal technique for the development of $\mathrm{p}$ type $\mathrm{ZnO}$ films owing to its simplicity and easy control of the composition at low cost [18-20]. To date, there is no report of $\mathrm{Na}$ doping of p-type $\mathrm{ZnO}$ nanorods by a hydrothermal method. Here, we report a simple, reliable, and low-cost method for growing and doping p-type $\mathrm{ZnO}$ nanorod arrays in aqueous solution, with $\mathrm{Na}$ as the p-type dopant.

\section{Experimental Section}

A high-resistance Si (100) wafer, the resistivity of which is above $500 \Omega \mathrm{cm}$, was used as the substrate. Precleaned silicon substrate was coated with a $\mathrm{ZnO}$ seed layer by sol-gel spin coating. $\mathrm{Zn}(\mathrm{AC})_{2} \cdot 2 \mathrm{H}_{2} \mathrm{O}$ were first dissolved in the mixture of 2-methoxyethanol and monoethanolamine. The molar ratio of monoethanolamine to $\mathrm{Zn}(\mathrm{AC})_{2} \cdot 2 \mathrm{H}_{2} \mathrm{O}$ was maintained at $1: 1$ and the concentration of $\mathrm{Zn}(\mathrm{AC})_{2} \cdot 2 \mathrm{H}_{2} \mathrm{O}$ was $75 \mathrm{mM}$. The sol was aged for $24 \mathrm{~h}$ at room temperature. The above 


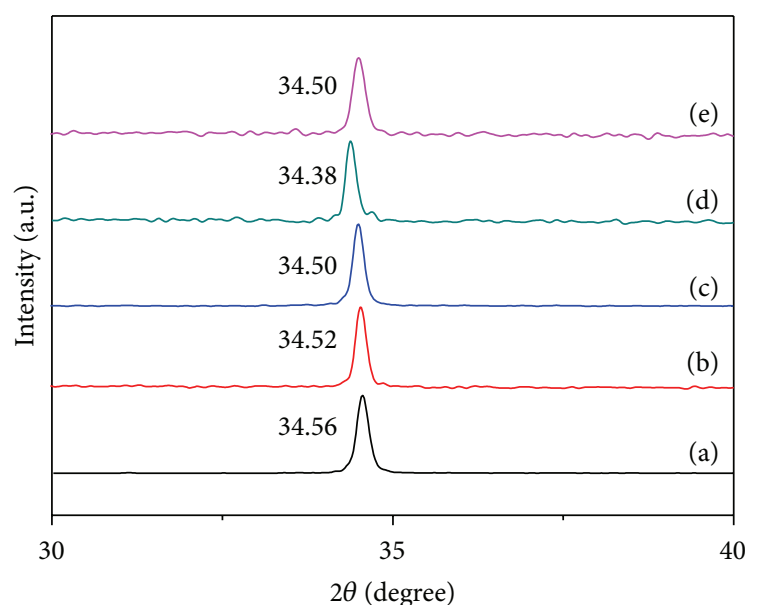

FIGURE 1: XRD patterns of the samples with $n_{\mathrm{Na}} / n_{\mathrm{Zn}}$ of (a) 0 , (b) 2.8 , (c) 5.6, (d) 8.4, and (e) 11.2.

solution was then spin-coated at $500 \mathrm{rpm}$ for $15 \mathrm{~s}$ and then at $5000 \mathrm{rpm}$ for $60 \mathrm{~s}$, followed by drying at $120^{\circ} \mathrm{C}$ for $15 \mathrm{~min}$. The procedure from coating to drying was repeated five times before the substrates were placed into a $360^{\circ} \mathrm{C}$ tube furnace in air for $20 \mathrm{~min}$ to form $\mathrm{ZnO}$ seed layer, evaporate the solvent, and remove any organic residue. Subsequently, $\mathrm{ZnO}$ nanorod arrays were grown directly by placing the substrate at the bottom of the beaker in $20 \mathrm{~mL}$ of aqueous solution of $12.5 \mathrm{mM} \mathrm{Zn}(\mathrm{AC})_{2} \cdot 2 \mathrm{H}_{2} \mathrm{O}, 12.5 \mathrm{mM}$ hexamethylenetetramine (HMTA, $\mathrm{C}_{6} \mathrm{H}_{12} \mathrm{~N}_{4}$ ), and different amounts of $\mathrm{NaCl}$ in a $50 \mathrm{~mL}$ autoclave. Different $\mathrm{Na}$ doping levels were obtained by varying the molar ratio of $\mathrm{Na} / \mathrm{Zn}\left(n_{\mathrm{Na}} / n_{\mathrm{Zn}}\right)(0,2.8,5.6,8.4$, and 11.2) in the precursor solution. Finally the autoclave was sealed and heated at $95^{\circ} \mathrm{C}$ for $2 \mathrm{~h}$. Subsequently, the samples are washed with deionized water for several times to remove the residual salt and amino complex and dried in a flow of nitrogen gas.

Powder X-ray diffraction (XRD) analyses were performed on a Philips PW-1830 X-ray diffractometer with $\mathrm{Cu} \mathrm{K} \alpha$ irradiation $(\lambda=1.5406 \AA)$ at a scanning speed of $0.014^{\circ} / \mathrm{sec}$ over the $2 \theta$ range of $30-40^{\circ}$. The electronic morphology of the samples was examined by Hitachi S- 4800 scanning electron microscope (SEM). The electrical properties were characterized by a Hall effect measurement system. Photoluminescence and Raman spectra of samples on Si substrate were recorded using Jobin-Yvon Lab-Ram high-resolution spectrometer with He-Cd laser $(\lambda=325 \mathrm{~nm})$.

\section{Results and Discussion}

XRD patterns of the hydrothermally grown samples were shown in Figure 1. The strong peak corresponding to $\mathrm{ZnO}$ (002) is observed in each film, which indicates high $c$-axis oriented in all samples. It can be seen that the diffraction peak shows an obvious shift to a smaller angle of about 34.56, $34.52,34.50,34.38$, and 34.52 for the sample with $n_{\mathrm{Na}} / n_{\mathrm{Zn}}$ of $0,2.8,5.6,8.4$, and 11.2 , respectively. This demonstrates that $\mathrm{Na}$ doping increases the lattice constant as a result of larger
TABLE 1: Electrical properties of $\mathrm{ZnO}$ films at room temperature.

\begin{tabular}{lccc}
\hline$n_{\mathrm{Na}} / n_{\mathrm{Zn}}$ & $\begin{array}{c}\text { Carrier } \\
\text { type }\end{array}$ & $\begin{array}{c}\text { Mobility } \\
\left(\mathrm{cm}^{2} \mathrm{v}^{-1} \mathrm{~s}^{-1}\right)\end{array}$ & $\begin{array}{c}\text { Carrier } \\
\text { concentration } \\
\left(\mathrm{cm}^{-3}\right)\end{array}$ \\
\hline 0 & $\mathrm{n}$ & 40 & $1.4 \times 10^{16}$ \\
2.8 & $\mathrm{p}$ & 106 & $3.1 \times 10^{16}$ \\
5.6 & $\mathrm{p}$ & 41.9 & $1.7 \times 10^{17}$ \\
8.4 & $\mathrm{p}$ & 99.4 & $6.5 \times 10^{16}$ \\
11.2 & $\mathrm{n}$ & 10.4 & $4.3 \times 10^{16}$ \\
\hline
\end{tabular}

TABLE 2: Electrical properties of Na-doped $\mathrm{ZnO}$ films by different processes.

\begin{tabular}{lccc}
\hline Material & $\begin{array}{c}\text { Mobility } \\
\left(\mathrm{cm}^{2} \mathrm{v}^{-1} \mathrm{~s}^{-1}\right)\end{array}$ & $\begin{array}{c}\text { Carrier concentration } \\
\left(\mathrm{cm}^{-3}\right)\end{array}$ & References \\
\hline $\mathrm{ZnO}: \mathrm{Na}$ & 1.41 & $5.19 \times 10^{16}$ & {$[9]$} \\
$\mathrm{ZnO}: \mathrm{Na}$ & $0.138-0.676$ & $6.90 \times 10^{16}-2.16 \times 10^{17}$ & {$[21]$} \\
$\mathrm{ZnO}: \mathrm{Na}$ & 0.22 & $5.3 \times 10^{16}$ & {$[22]$} \\
$\mathrm{ZnO}: \mathrm{Na}$ & 0.43 & $2.5 \times 10^{17}$ & {$[23]$} \\
$\mathrm{ZnO}: \mathrm{Na}$ & 0.402 & $1.81 \times 10^{15}$ & {$[24]$} \\
$\mathrm{ZnO}: \mathrm{Na}$ & 2.1 & $1.3 \times 10^{16}$ & {$[7]$} \\
nanowires & & $3.1 \times 10^{16}-1.7 \times 10^{17}$ & Our work \\
$\begin{array}{l}\mathrm{ZnO}: \mathrm{Na} \\
\text { nanorod arrays }\end{array}$ & $41.9-106$ & &
\end{tabular}

ionic radius of $\mathrm{Na}^{+}(0.089 \mathrm{~nm})$ compared with that of $\mathrm{Zn}^{2+}$ $(0.070 \mathrm{~nm})[8]$.

Figure 2 shows the surface morphologies of samples grown by simple aqueous solution approach on Si substrates. The nanorods are vertically well-aligned on the substrate surface. The diameter and length of pure $\mathrm{ZnO}$ are in the range of around $30 \mathrm{~nm}$ and $754 \mathrm{~nm}$, respectively. Figure 3 shows a plot of diameter and length of $\mathrm{ZnO}$ nanorod arrays as functions of $n_{\mathrm{Na}} / n_{\mathrm{Zn}}$. With the increase of $n_{\mathrm{Na}} / n_{\mathrm{Zn}}$, the diameter of $\mathrm{ZnO}$ nanorod increased to $50 \mathrm{~nm}, 60 \mathrm{~nm}, 70 \mathrm{~nm}$, and $70 \mathrm{~nm}$, and the length decreased to $150 \mathrm{~nm}, 112 \mathrm{~nm}$, $98 \mathrm{~nm}$, and $71 \mathrm{~nm}$, respectively.

Table 1 summarizes the electrical properties of $\mathrm{ZnO}$ films. Under Hall effect measurements, the undoped sample showed n-type conductivity, while the doped sample with $n_{\mathrm{Na}} / n_{\mathrm{Zn}}$ of 2.8-8.4 showed p-type conductivity, but when $n_{\mathrm{Na}} / n_{\mathrm{Zn}}$ was increased to 11.2 , the film showed $\mathrm{n}$-type conductivity again. In contrast, the electrical properties of samples with $n_{\mathrm{Na}} / n_{\mathrm{Zn}}$ of 2.8-8.4 showed higher mobility and carrier concentration. Mobility was up to $106 \mathrm{~cm}^{2} \mathrm{v}^{-1} \mathrm{~s}^{-1}$ when $n_{\mathrm{Na}} / n_{\mathrm{Zn}}$ was 2.8 , and the carrier concentration was $1.7 \times 10^{17} \mathrm{~cm}^{-3}$ when $n_{\mathrm{Na}} / n_{\mathrm{Zn}}$ was 5.6. Mobility and carrier concentration were significantly improved by doping. We think this is due to the right amount of $\mathrm{Na}$ ions in the $\mathrm{Zn}$ lattice sites acting as acceptors, compensation $\mathrm{Zn}_{\mathrm{i}}$, and $\mathrm{V}_{\mathrm{O}}$ intrinsic donor defects in the lattice. Most of the $\mathrm{Na}^{+}$occupies the lattice position, and the lattice expansion is small. The above XRD analysis further illustrates the rationality of our analysis. Electrical properties of $\mathrm{Na}$-doped $\mathrm{ZnO}$ films by different processes are shown in Table 2. It can be seen that 


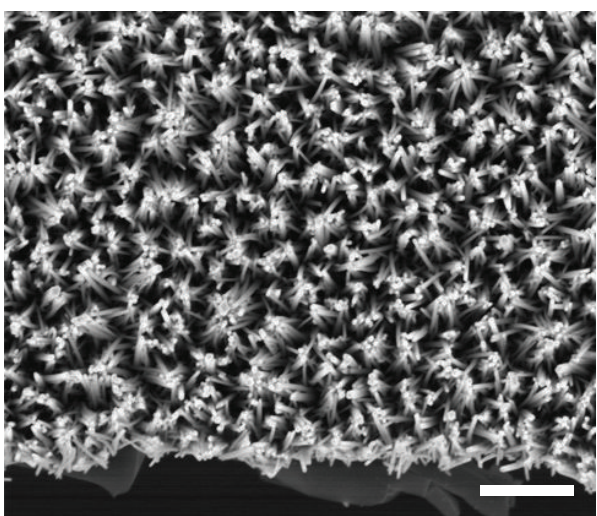

(a)

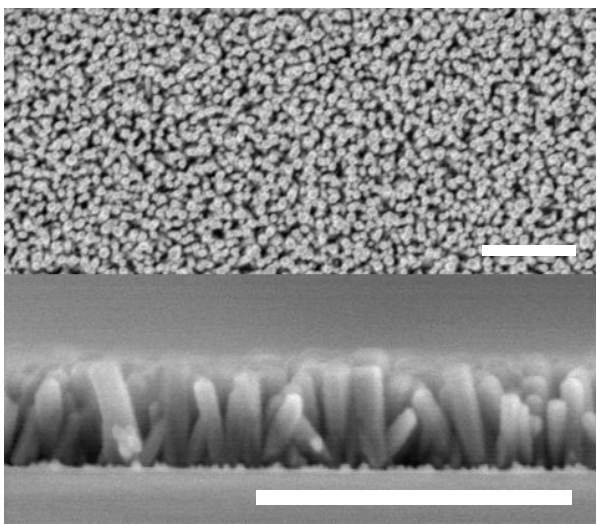

(c)

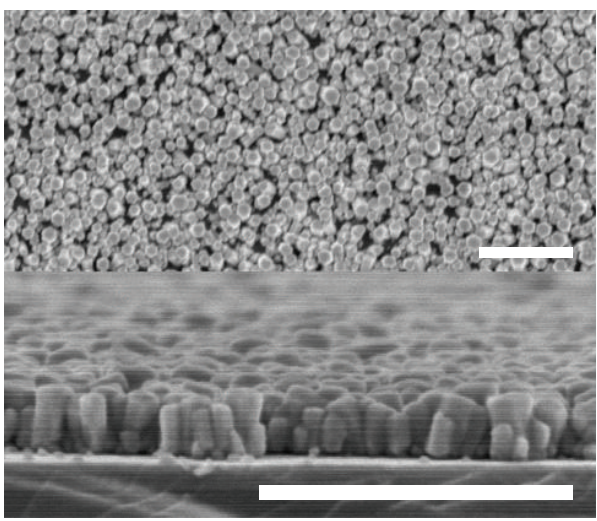

(e)

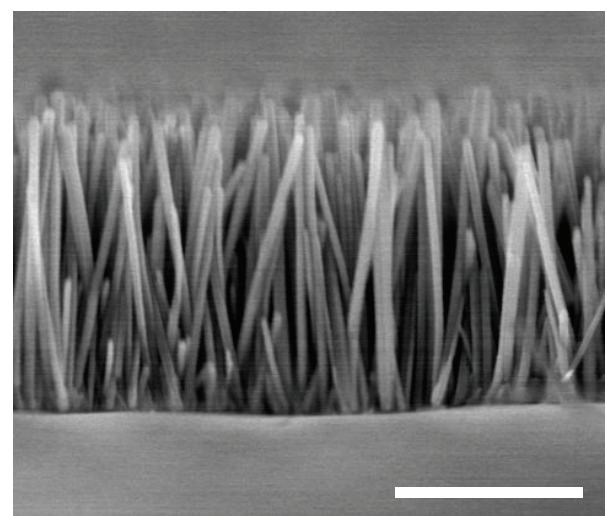

(b)

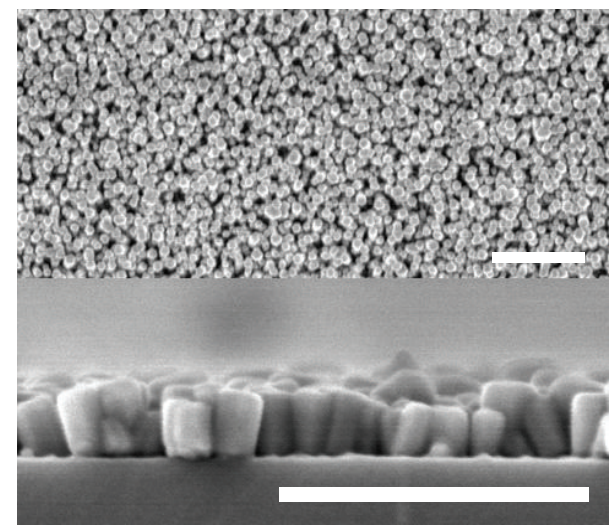

(d)

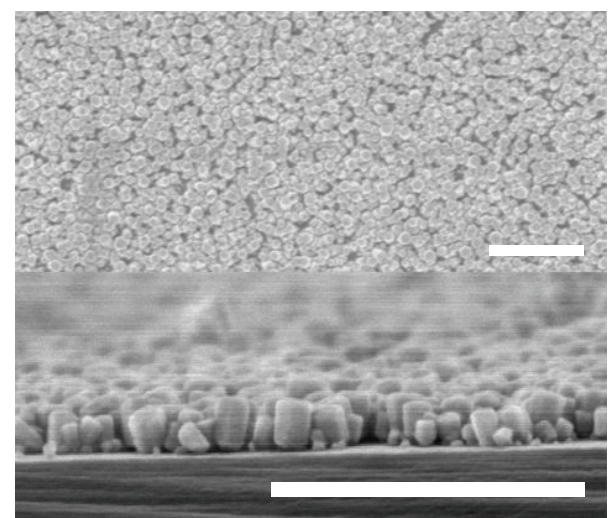

(f)

Figure 2: SEM images of the samples with $n_{\mathrm{Na}} / n_{\mathrm{Zn}}$ of (a, b) 0, (c) 2.8, (d) 5.6, (e) 8.4, and (f) 11.2. All the scale bars are $500 \mathrm{~nm}$.

Na-doped nanorod arrays in this study showed excellent electrical properties.

Usually, PL spectra of $\mathrm{ZnO}$ at room temperature were composed of a near band edge UV emission peak at around $375 \mathrm{~nm}$ and a deep level green emission peak at 450$550 \mathrm{~nm}$. Researchers generally believe that the near band edge UV emission peak was caused by the recombination luminescence of the band edge exciton, while the deep level green emission peak was caused by the recombination of the defects such as $\mathrm{O}$ vacancy and $\mathrm{Zn}$ interstitial. Strong excitonic emission at $375 \mathrm{~nm}$ was observed, as shown in Figure 4. The UV emission was so strong, which indicates that all the $1 \mathrm{D}$
$\mathrm{ZnO}$ arrays were of high UV emission efficiency and that the green emission could hardly be observed in the PL spectrum, indicating that the crystalline quality of $\mathrm{ZnO}$ was high and lattice oxygen vacancy concentration is very low.

Figure 5 shows the doped samples before and after $325 \mathrm{~nm}$ excitation of Raman spectra. Raman spectra can be sensitive to detect the crystallization of the material and the defect state. Undoped $\mathrm{Al}(\mathrm{LO})$ mode peak at $578.1 \mathrm{~cm}^{-1}$ corresponds to the El longitudinal optical phonon (LO) mode. When the molar ratio of $\mathrm{Na}$ and $\mathrm{Zn}$ was $2.8,5.6,7.8$, and 11.2, the peak position was at $577.3 \mathrm{~cm}^{-1}, 574.9 \mathrm{~cm}^{-1}, 574.2 \mathrm{~cm}^{-1}$, and $575.8 \mathrm{~cm}^{-1}$, which moved $0.8 \mathrm{~cm}^{-1}, 3.2 \mathrm{~cm}^{-1}, 3.9 \mathrm{~cm}^{-1}$, 


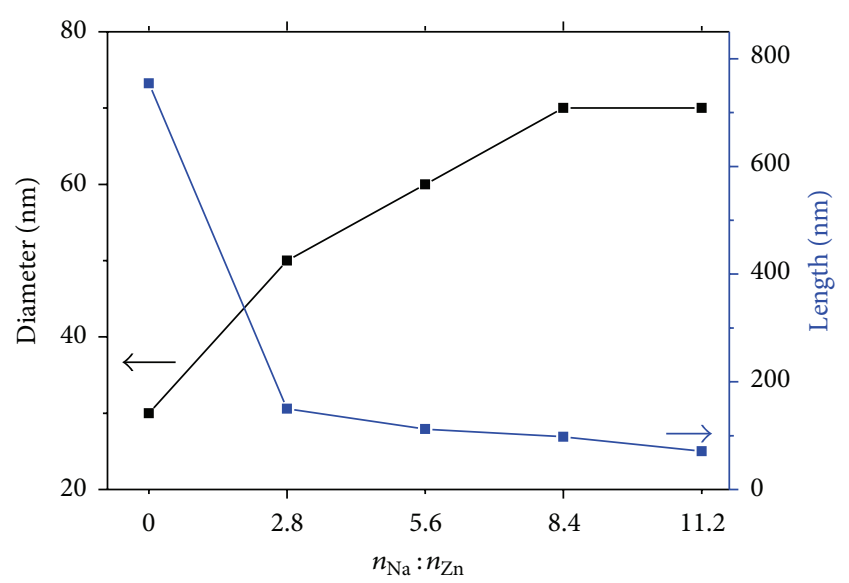

Figure 3: Diameter and length of $\mathrm{ZnO}$ nanorod arrays as functions of $n_{\mathrm{Na}} / n_{\mathrm{Zn}}$.

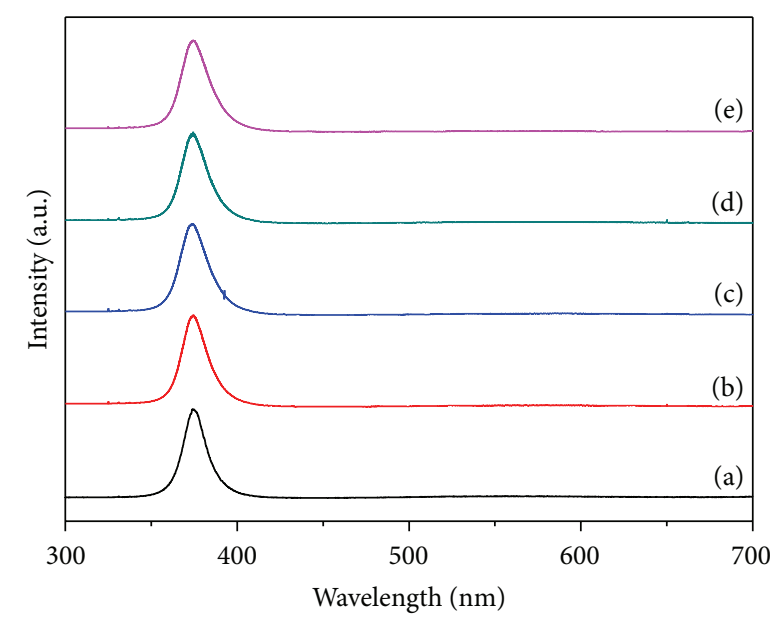

FigURE 4: PL spectrum of the samples with $n_{\mathrm{Na}} / n_{\mathrm{Zn}}$ of (a) 0 , (b) 2.8 , (c) 5.6, (d) 8.4, and (e) 11.2.

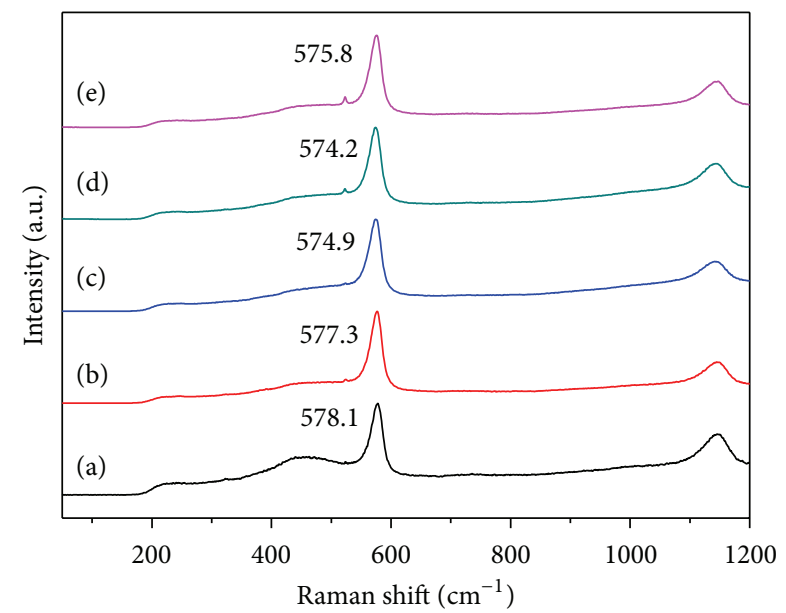

FIgURE 5: Raman spectra of the samples with $n_{\mathrm{Na}} / n_{\mathrm{Zn}}$ of (a) 0 , (b) 2.8, (c) 5.6, (d) 8.4, and (e) 11.2.

and $2.3 \mathrm{~cm}^{-1}$, respectively. We observed that the peaks move to lower frequency, because this peak and the oxygen atom vacancies and zinc atoms interstitial related to its move reflect the changes in the concentration of free carriers in the $\mathrm{ZnO}$ crystal. So the concentration of free carriers in the $\mathrm{ZnO}$ crystals doped $\mathrm{Na}$ changed, and when the doping concentration of $\mathrm{Al}$ ( $\mathrm{LO}$ ) peak of the amount of movement is also different, this also shows the degree of change of free carrier concentration to be different.

\section{Conclusion}

In summary, $\mathrm{Na}$-doped $\mathrm{ZnO}$ nanorod arrays with high crystalline quality were successfully fabricated on $\mathrm{Si}$ substrate by a simple hydrothermal method for the first time. With the increase of $n_{\mathrm{Na}} / n_{\mathrm{Zn}}$, the diameter of $\mathrm{ZnO}$ nanorod gradually increased from $30 \mathrm{~nm}$ to $70 \mathrm{~nm}$, and the length decreased from $754 \mathrm{~nm}$ to $71 \mathrm{~nm}$. Structural, electrical, and optical properties were investigated. The p-type carrier concentrations and mobility of $\mathrm{Na}$-doped $\mathrm{ZnO}$ nanorod arrays arranged from $3.1 \times 10^{16} \mathrm{~cm}^{-3}$ to $1.7 \times 10^{17} \mathrm{~cm}^{-3}$ and $41.9 \mathrm{~cm}^{2} \mathrm{v}^{-1} \mathrm{~s}^{-1}$ to $106 \mathrm{~cm}^{2} \mathrm{v}^{-1} \mathrm{~s}^{-1}$, respectively.

\section{Competing Interests}

The authors declare that there are no competing interests regarding the publication of this paper.

\section{Acknowledgments}

This study is supported by the National Natural Science Foundation of China (no. 51402252) and the Natural Science Foundation of Jiangsu Province (no. BK20140463).

\section{References}

[1] Y. X. Liu, H. L. Zhang, Z. X. Zhang, Y. Z. Xie, and E. Q. Xie, "Conversion of p-type to n-type conductivity in undoped $\mathrm{ZnO}$ films by increasing operating temperature," Applied Surface Science, vol. 257, no. 4, pp. 1236-1238, 2010.

[2] M. Ding, D. X. Zhao, B. Yao, B. H. Li, Z. Zhang, and D. Shen, "The p-type $\mathrm{ZnO}$ film realized by a hydrothermal treatment method," Applied Physics Letters, vol. 98, no. 6, Article ID 062102, 2011.

[3] Y. T. Shih, J. F. Chien, M. J. Chen, J. R. Yang, and M. Shiojiri, "P-type ZnO:P films fabricated by atomic layer deposition and thermal processing," Journal of the Electrochemical Society, vol. 158, no. 5, pp. H516-H520, 2011.

[4] V. Vaithianathan, B.-T. Lee, and S. S. Kim, "Preparation of Asdoped $p$-type $\mathrm{ZnO}$ films using a $\mathrm{Zn}_{3} \mathrm{As}_{2} \mathrm{ZnO}$ target with pulsed laser deposition," Applied Physics Letters, vol. 86, no. 6, Article ID 062101, 2005.

[5] F. Friedrich, I. Sieber, C. Klimm, M. Klaus, C. Genzel, and N. $\mathrm{H}$. Nickel, "Sb-doping of $\mathrm{ZnO}$ : phase segregation and its impact on p-type doping," Applied Physics Letters, vol. 98, no. 13, Article ID 131902, 2011.

[6] Y. J. Zeng, Z. Z. Ye, W. Z. Xu et al., "Dopant source choice for formation of p-type ZnO: Li acceptor," Applied Physics Letters, vol. 88, no. 6, Article ID 062107, 2006.

[7] W. Liu, F. X. Xiu, K. H. Sun et al., "Na-doped p-type ZnO microwires," Journal of the American Chemical Society, vol. 132, no. 8, pp. 2498-2499, 2010. 
[8] L. Q. Zhang, Y. Z. Zhang, Z. Z. Ye et al., "The fabrication of Na doped p-type $\mathrm{Zn}_{1--x} \mathrm{Mg}_{x} \mathrm{O}$ films by pulsed laser deposition," Applied Physics A: Materials Science and Processing, vol. 106, no. 1, pp. 191-196, 2012.

[9] Y. Li, Y. Z. Zhang, H. P. He, Z. Z. Ye, J. Jiang, and L. Cao, "Growth of $\mathrm{Na}$ doped p-type non-polar a-plane $\mathrm{ZnO}$ films by pulsed laser deposition," Materials Letters, vol. 76, pp. 81-83, 2012.

[10] M. K. Gupta, N. Sinha, and B. Kumar, "p-type K-doped ZnO nanorods for optoelectronic applications," Journal of Applied Physics, vol. 109, no. 8, Article ID 083532, 2011.

[11] M. A. Myers, J. H. Lee, Z. X. Bi, and H. Y. Wang, "High quality ptype Ag-doped $\mathrm{ZnO}$ thin films achieved under elevated growth temperatures," Journal of Physics-Condensed Matter, vol. 24, no. 22, Article ID 229501, 2012.

[12] B. Marí, M. Sahal, M. A. Mollar, F. M. Cerqueira, and A. P. Samantilleke, "p-Type behaviour of electrodeposited $\mathrm{ZnO}: \mathrm{Cu}$ films," Journal of Solid State Electrochemistry, vol. 16, no. 6, pp. 2261-2265, 2012.

[13] C. H. Park, S. B. Zhang, and S.-H. Wei, "Origin of p-type doping difficulty in $\mathrm{ZnO}$ : the impurity perspective," Physical Review BCondensed Matter and Materials Physics, vol. 66, no. 7, Article ID 073202, 2002.

[14] B. Y. Zhang, B. Yao, Y. F. Li et al., "Investigation on the formation mechanism of p-type Li-N dual-doped ZnO," Applied Physics Letters, vol. 97, no. 22, Article ID 222101, 2010.

[15] M. Suja, S. B. Bashar, M. M. Morshed, and J. L. Liu, "Realization of $\mathrm{Cu}$-doped p-type $\mathrm{ZnO}$ thin films by molecular beam epitaxy," ACS Applied Materials \& Interfaces, vol. 7, no. 16, pp. 8894-8899, 2015.

[16] S. B. Bashar, M. Suja, M. Morshed, F. Gao, and J. Liu, "An Sb-doped p-type $\mathrm{ZnO}$ nanowire based random laser diode," Nanotechnology, vol. 27, no. 6, Article ID 065204, 2016.

[17] L. Cao, L. P. Zhu, J. Jiang, Y. Li, Y. Z. Zhang, and Z. Z. Ye, "Preparation and properties of p-type Ag-doped $\mathrm{ZnMgO}$ thin films by pulsed laser deposition," Journal of Alloys and Compounds, vol. 516, pp. 157-160, 2012.

[18] X. Fang, J. H. Li, D. Zhao, D. Shen, B. Li, and X. Wang, "Phosphorus-doped p-Type $\mathrm{ZnO}$ nanorods and $\mathrm{ZnO}$ nanorod $\mathrm{p}$ n homojunction LED fabricated by hydrothermal method," Journal of Physical Chemistry C, vol. 113, no. 50, pp. 21208-21212, 2009.

[19] S. N. Das, J.-H. Choi, J. P. Kar, T. I. Lee, and J.-M. Myoung, "Fabrication of p-type $\mathrm{ZnO}$ nanowires based heterojunction diode," Materials Chemistry and Physics, vol. 121, no. 3, pp. 472476, 2010 .

[20] Q. X. Xia, K. S. Hui, K. N. Hui et al., "High quality p-type Ndoped AZO nanorod arrays by an ammonia-assisted hydrothermal method," Materials Letters, vol. 78, pp. 180-183, 2012.

[21] Z. Zheng, Y. F. Lu, Z. Z. Ye, H. P. He, and B. H. Zhao, "Carrier type- and concentration-dependent absorption and photoluminescence of $\mathrm{ZnO}$ films doped with different $\mathrm{Na}$ contents," Materials Science in Semiconductor Processing, vol. 16, no. 3, pp. 647-651, 2013.

[22] X. H. Pan, Y. S. Zhou, S. S. Chen et al., "Effect of Na contents on fabrication of p-type non-polar m-plane $\mathrm{ZnO}$ films," Journal of Crystal Growth, vol. 404, pp. 54-58, 2014.

[23] W. Chen, X. H. Pan, S. S. Chen et al., "Investigation on nonpolar m-plane $\mathrm{ZnO}$ and $\mathrm{Na}$-doped p-type $\mathrm{ZnO}$ films grown by plasma-assisted molecular beam epitaxy," Applied Physics A: Materials Science and Processing, vol. 121, no. 1, pp. 77-82, 2015.
[24] P. Ding, X. H. Pan, Z. Z. Ye et al., "Realization of p-type nonpolar a-plane $\mathrm{ZnO}$ films via doping of $\mathrm{Na}$ acceptor," Solid State Communications, vol. 156, pp. 8-11, 2013. 

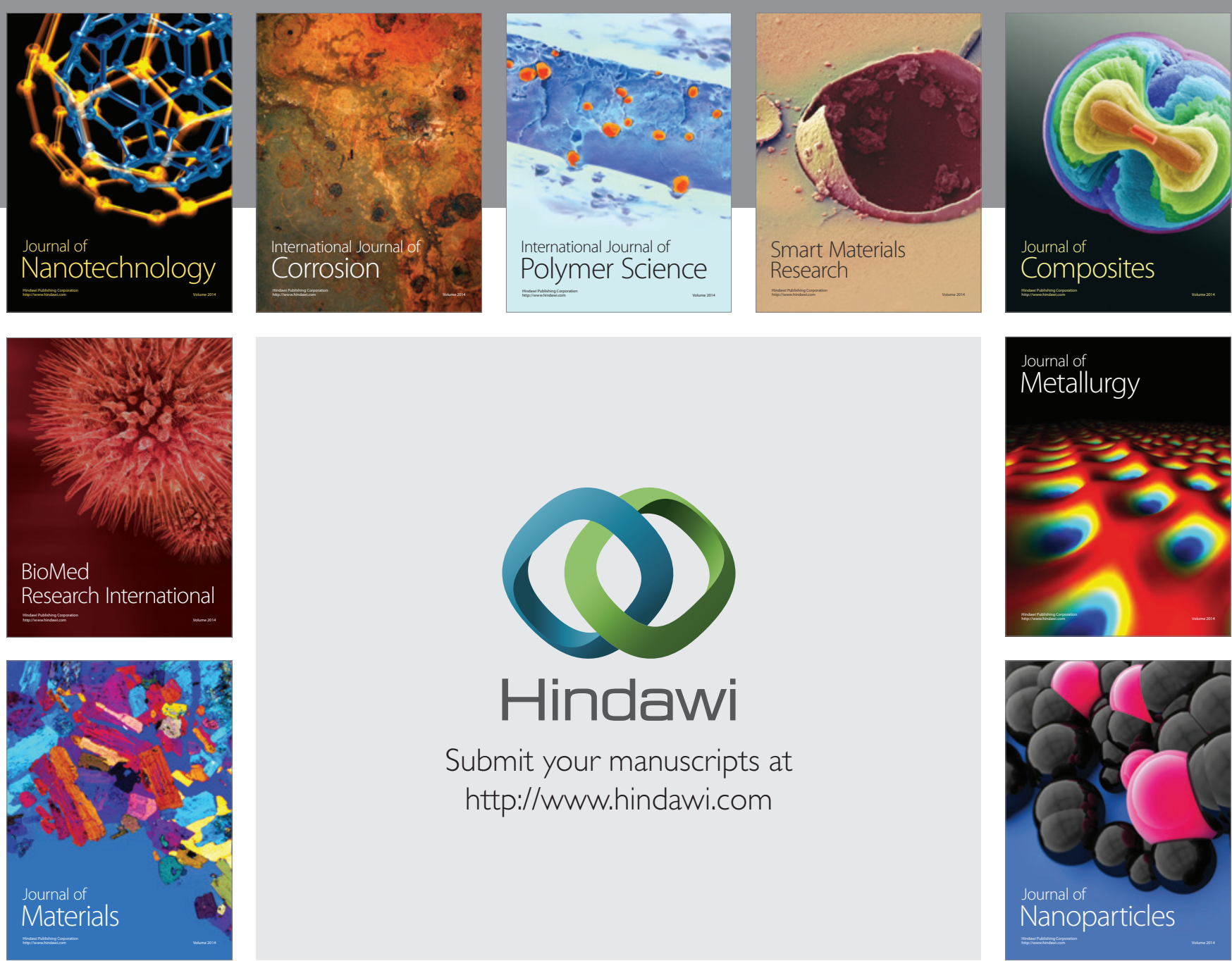

\section{Hindawi}

Submit your manuscripts at

http://www.hindawi.com

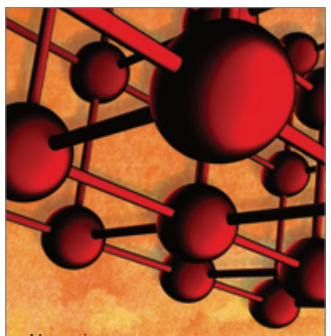

Materials Science and Engineering
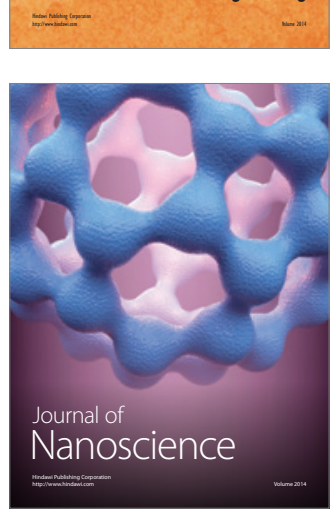
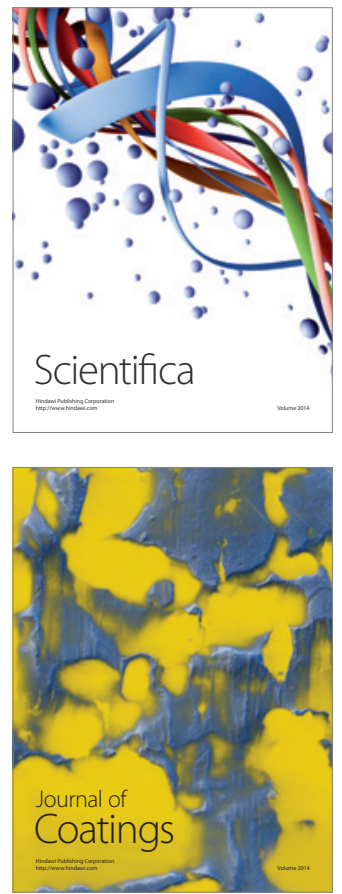
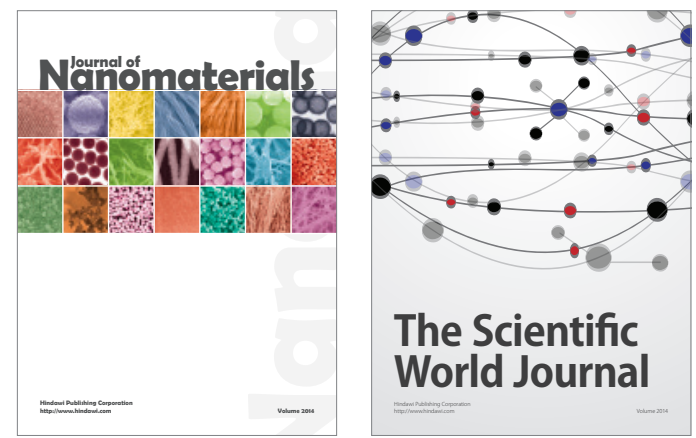

The Scientific World Journal
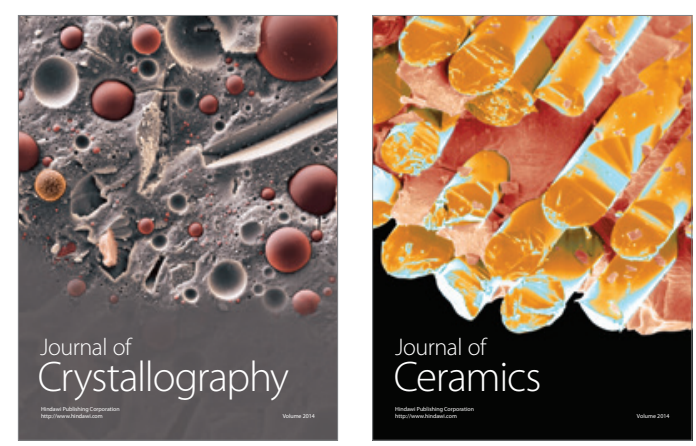
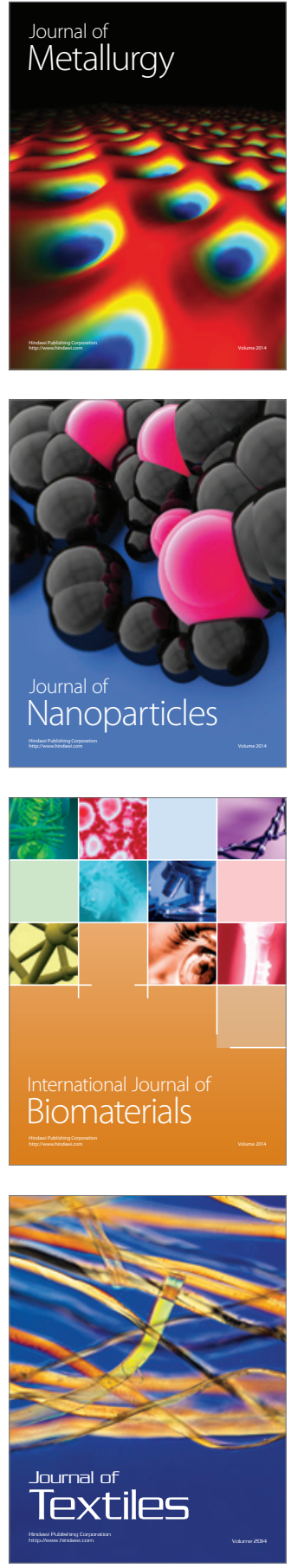